\title{
HESIOD, FR. 24 MW
}

The text of the Fragment is easy to restore, if one does account for the late pronunciation of the Greek language: $\eta$ as i, $u$ as i, $\vartheta$ and $\delta$ as (engl.) th resp. "dh". Instead of the impossibility of two fathers of Helen emerges the reading ' $2 \kappa \varepsilon a-$

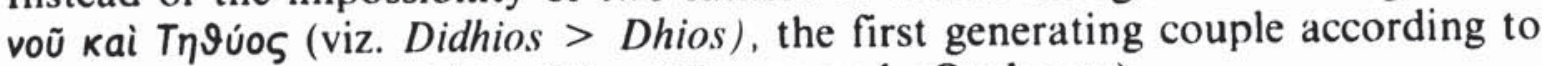
old tradition (Homer and "Orpheus").

Man darf voraussetzen: Wie Kore-Persephone zum Götterpaar Zeus

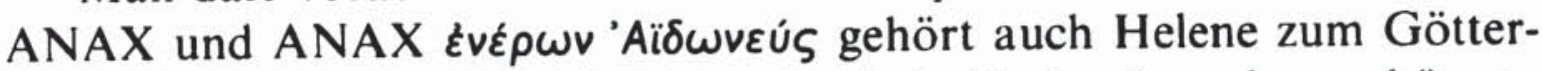

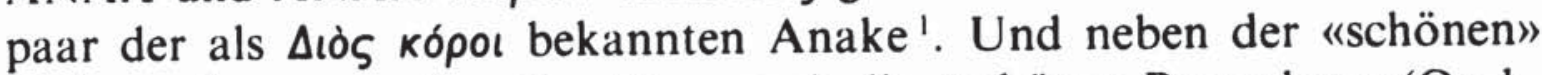
Helene gibt es aus alter Tradition auch die «schöne» Persephone (Orph. Hy. 29,9 f.). Für beide Göttinnen sind «Raub» (Entführung) und «Wiederkehr» das Wesentliche ihres Mythos. Helene ist also im Ursprung eine altera Kore-Persephone. Und das dürfte wohl gerade in ältesten Überlieferungen am ehesten hervortreten. Um ein Testimonium für Altertümliches geht es auch in dem hier zu besprechenden Scholion.

Hes. fr. $24 \mathrm{MW}=$ Schol. Pind: Nem. X 150. Die beiden Codd. B

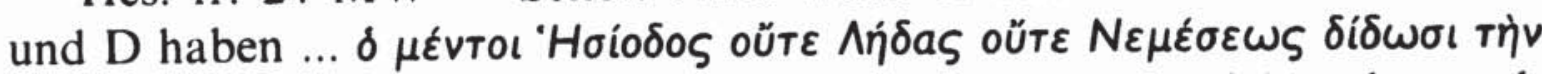

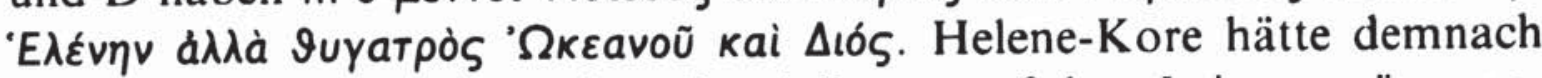
eine Okeanide als Mutter, ihre Gespielinnen auf dem Leimon wären somit ihre Tanten. Schwer verständlich ist schon dies, und vollends unverständlich bliebe dabei, warum diese Mutter nicht mit Namen genannt wird. Nun hat die Editio Romana von 1515 aber dies: ... àd à

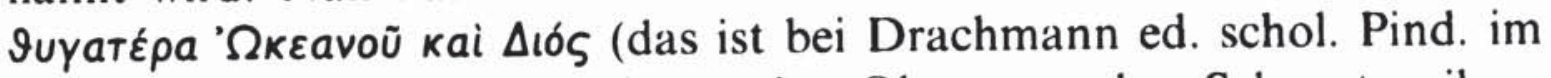
Apparat verzeichnet). Tochter des Okeanos, also Schwester ihrer Gespielinnen, ist zwar sehr wohl verständlich: aber zwei Väter sind nicht möglich. Der Fehler läge dann an dem $\Delta$ iós, und das Richtige ist

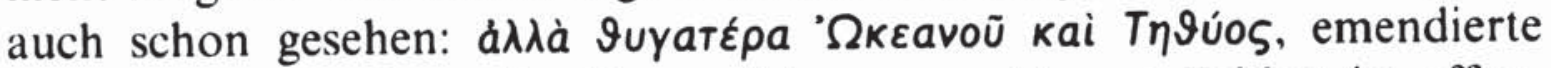
Beck (ed. 1815). Denn das Zustandekommen dieses Fehlers ist offen-

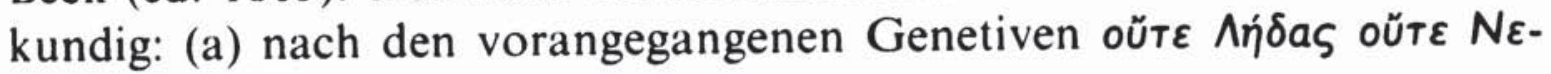

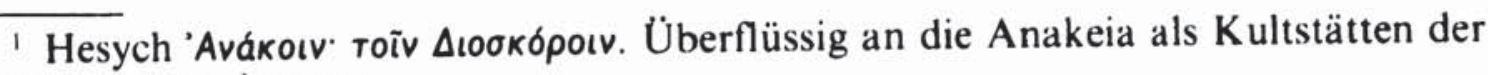
Dioskuren zu erinnern. 


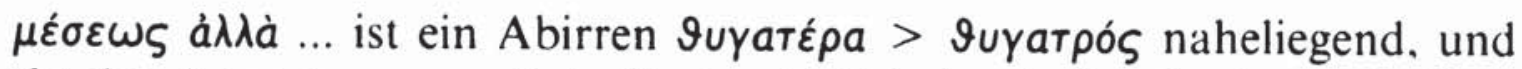
(b) das $\Delta$ ió ist aussprachebedingt, nämlich durch den Itazismus in Verbindung mit der Aussprache der Dentale: das $T$ ist wie alle Tenues unbehaucht, kommt daher dem "D» näher als dem «deutsch» gesprochenen $T$, das $\theta$ ist nach der Theorie der neugriechischen Grammatik stimmloses th wie in englisch "thing», kommt aber de facto dem stimmhaften $\Delta=\mathrm{dh}$ (engl. "that») sehr nahe, sodass ein gehörtes Didhios zu $\Delta$ ós $=$ dhios nicht nur werden $\mathrm{k}$ on $\mathrm{nte}$ sondern - nach dem vorange-

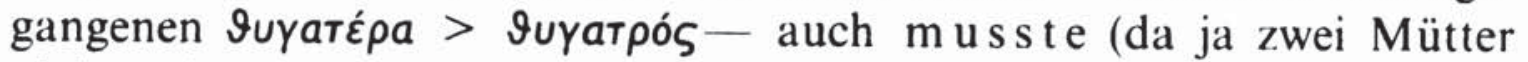
nicht stehen bleiben durften).

Dabei ist kaum zu entscheiden (und auch nicht wichtig), ob zuerst der psychologisch verständliche Irrtum Эuүarépa > ९uүarpós eintrat, der dann - weil zwei Mütter nicht möglich waren-- die Änderung

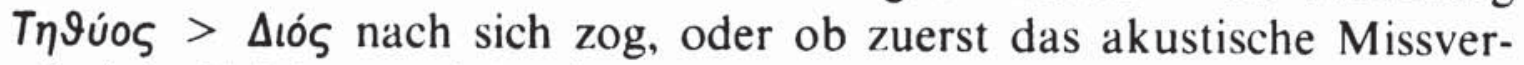

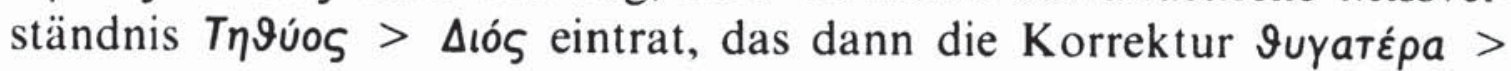
Эuүaтpós erforderte, weil ja keine zwei Väter stehen bleiben durften. In jedem der beiden möglichen Fälle ist aber evident, dass das Eine notwendig das Andere bedingt, dass also so oder so nur Ein Fehler zu Grunde liegt.

Den derart überzeugend emendierten Text liest man bereits in Pindari Carmina iterum cur. Chr. Gottl. Heyne (vol. II, p. 784 f.): ... à $\lambda \lambda \dot{a}$

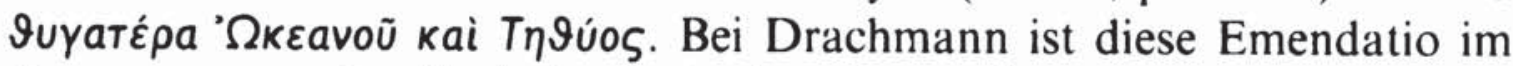
Apparat vermerkt. Und ein Bethe hat sie anerkannt $(R E 7,2,2828,1$ ff.).

Für diese altertümliche Abstammung der Helene von Okeanos und Tethys ist noch anzuführen: bei Kenchreai bei Korinth gab es einen

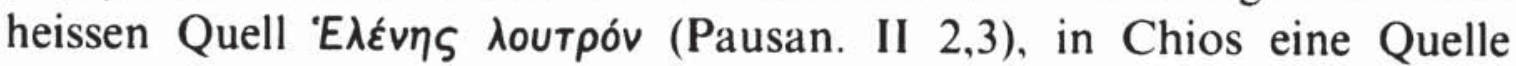

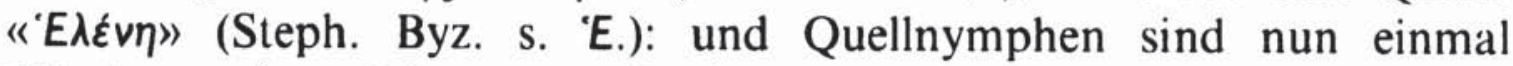
Töchter des Okeanos (Orph. Hy. 51, Hes. Th. 346 ff., Il. XXI 195-97, Soph. fr. 248 N. ${ }^{2}$, u.a.). Insofern bringt Becks Emendation nicht einmal etwas Neues oder Entlegenes.

Der Helene alte Abkunft von Okeanos und Tethys bedeutet nun aber auch, dass sie unmittelbar von dem nach Orpheus ersten zeugenden Paare abstammt:

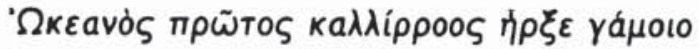

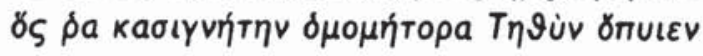

(Orph. fr. 15 K., vgl. Hes. Th. 337 ff., Il. XIV 201) 2. Und wenn Hesiod dieser Abstammung folgt, so ist dies wiederum einer der bemer-

${ }^{2}$ Zum Verhältnis des Il. XIV zu "Orpheus» s. W. Theiler, Unters. z. ant. Lit. 21 ff., $24 \mathrm{f}$. 


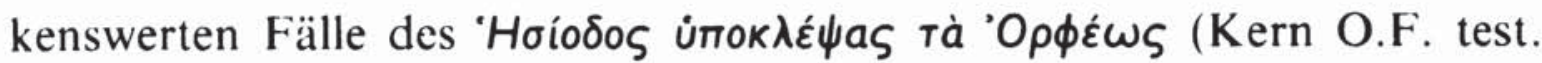
246, dazu Böhme, Orpheus, 49, 5, und Sänger der Vorzeit, 16 ff.). Dass sekundär wie die Anake zu Dioskuren so auch Helene zur Dios Kora wurde, besagt ja für Hesiod nichts. Diese schliessliche Abstammung von Zeus hat überhaupt keine besondere Bedeutung (Wilamowitz, Gl. $d$. H., I 186, und Herter $R E 17,2,1528,48 \mathrm{ff}$.).

Die von West in der neuen Ausgabe der Fragmenta Hesiodea (MW) vorgeschlagene willkürliche Textänderung - mit völliger Beseitigung des Namens Hesiod, dessen Ersetzung durch ó rà Kúmpıa noı́rбas, Ein-

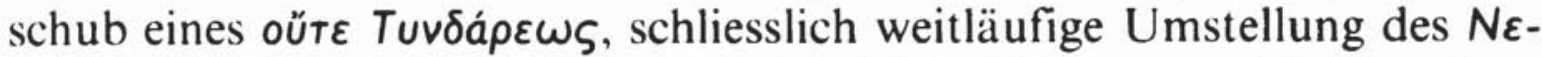

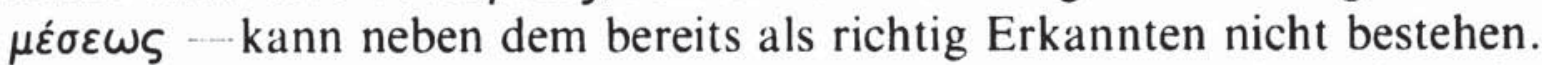
Es ist sehr zu bedauern, dass in dieser auf lange Zeit gültigen Ausgabe der Hesiodfragmente im Apparat nur die eigenwillige Text-Umgestaltung Wests geboten wird, ohne jeglichen Hinweis auf die Lesart der Ed. Romana oder gar die überzeugende Emendation Becks.

Dadurch ist ein dreifach bemerkenswertes Zeugnis auf lange Zeit verschüttet: 1) eine durch ihre Altertümlichkeit oder gar Primordialität überaus wertvolle Tradition bei Hesiod, 2) eine weit zurückreichende und recht urtümliche Abkunft der Helene als Göttin, die sie den andern Ausgestaltungen der Vegetationsgöttin (Kore-Persephone, Hagna, Ariadne $=$ Arihagna, u.a. $)^{3}$ näher rückt, 3) ein weiterer Fall des Hesiod als "Orpheus-Hypoklepten", auch wenn diese Interrelation der beiden Grossen Sänger infolge der noch nicht überwundenen Lobeck-Kernschen Theorie heute noch kaum geschätzt wird.

ROBERT BÖHME:

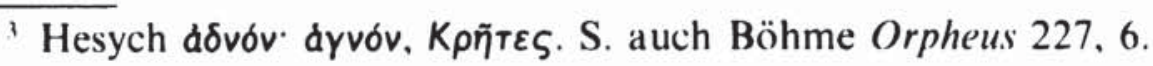

